\title{
Non-linear Inflationary Dynamics: Evidence from the UK
}

\author{
Michael Arghyrou \\ Christopher Martin \\ Costas Milas* \\ Department of Economics and Finance \\ Brunel University \\ UK
}

January 2003

\begin{abstract}
This paper estimates a variety of models of inflation using quarterly data for the UK between 1965 and 2001. We find strong evidence that the persistence of inflation is nonlinear and that inflation adjusted more rapidly in periods of macroeconomic stress such as the mid-1970s, the early 1980s and the late 1980s-early 1990s. Our results imply that inflation will respond more strongly and more rapidly to changes in interest rates when the price level is further away from the steady state level. This has implications for optimal monetary policy.
\end{abstract}

Keywords: inflation persistence, monetary policy, non linear adjustment JEL Classification: C51; C52; E31

* Address for correspondence: Prof Chris Martin, Department of Economics and Finance, Brunel University, Uxbridge, Middlesex UB8 3PH, UK Phone (+44) (0)1895 203171; Fax (+44) (0)1895 203384;

Email christopher.martin@brunel.ac.uk

We thank Mike Clements, Jerry Coakley, Denise Osborn and seminar participants at Leicester for their comments. 


\section{Non-linear Inflationary Dynamics: Evidence from the UK}

\section{1) Introduction}

Milton Friedman famously argued that the impact of changes in monetary policy on inflation is subject to "long and variable lags". Long lags, it was argued, are caused by highly persistent inflation. Variable lags are caused by variations in the persistence of inflation. Modern macroeconomics has absorbed the first part of Friedman's statement. Current estimates suggest that the greatest impact on inflation of current policy actions is felt 4-8 quarters ahead (e.g. Bank of England, 1999, Batini and Nelson, 2002). Inflation persistence is reflected in recent theoretical analyses of monetary policy (e.g. Svensson, 1997, Clarida et al, 1999).

By contrast, the second part of Friedman's statement has had much less impact. Variable lags in the impact of monetary policy require a nonlinear model of inflation persistence. However, almost all empirical models are linear. In this paper, we consider three main questions. First, is inflation adjustment linear or nonlinear? Second, if nonlinear, what form does the nonlinearity take? Third, what are the dangers in using a linear model of inflation?

We consider two aspects of non-linearity. We investigate the size hypothesis, which argues that inflation adjusts faster when the price level is further from its equilibrium or steady-state level. This will occur if, for example, more firms choose to adjust price when the price level is further from the steady-state, as argued by Ball and Mankiw (1995). We also investigate the asymmetry hypothesis, which argues that inflation persistence when the price level is above its steady-state level differs from inflation persistence when the price level is below the steady-state level. Theory does not provide a clear prediction about the direction of this effect. Some models predict that inflation will adjust more rapidly when prices are "too low", that is below the steady-state level. This is because the gap between the price level and the steady-state price level will be eroded by inflation if prices are "too low" but will increase if prices are "too high" (see, for example, Ball and Mankiw, 1995). However this prediction can be reversed in more competitive 
markets where high prices may provoke entry (see, for example, Bennett and La Mana, 2001).

We estimate a variety of models of inflation persistence using quarterly data for the UK between 1965 and 2001. We have a number of findings. We find strong evidence that the persistence of inflation is non-linear as non-linear models consistently outperform the linear model. Estimates of nonlinear models reveal that inflation is normally highly persistent, but becomes less persistent in periods of "macroeconomic stress", such as the inflationary episode of the mid-1970s, the severe recession of the early 1980 s and in the early 1990s. There is clear and robust support for the size hypothesis in the nonlinear models that we estimate. In our preferred model of inflation persistence, we find that the persistence of inflation is lower when the price level is more than $3.5 \%$ away from the steady state level. There is also support for the asymmetry hypothesis in our preferred model, where we find that inflation is less persistent when prices are above the steady state. Estimates of other models, however, provide less support for the asymmetry hypothesis.

These findings have clear policy implications since variable lags in the persistence of inflation will affect the optimal timing and extent of policy changes. In particular, our finding that inflation adjusts more rapidly when prices are further from the steady state suggests that inflation may be more responsive to monetary policy in periods of "macroeconomic stress". Finally, we note that there are dangers in using linear models of inflation persistence. These models find that inflation is always highly persistent and cannot account for the variations in persistence we detect using nonlinear models. Linear models may therefore be seriously misleading in periods of macroeconomics stress, when persistence is lower. This suggests that ignoring the second part of Friedman's statement by relying on linear models may result in systematic mistakes in monetary policy, a problem that is most severe in periods of greatest difficulty.

\section{2) A Baseline Linear Model}


Using quarterly data, the typical structure of conventional linear models of inflation persistence is as follows:

$$
\Delta_{4} p_{t}=\beta(L) \Delta_{4} p_{t-1}+\gamma(L) \Delta_{4} p^{*}+\delta\left(p-p^{*}\right)_{t-4}+\varepsilon_{t}
$$

where $p$ is the price level, $\Delta_{4} p_{t}=p_{t}-p_{t-4}$ is the inflation rate, $p^{*}$ is the steadystate or equilibrium value of the price level, $\beta(L)$ and $\gamma(L)$ are polynomials in the lag operator, $L, \varepsilon$ is a white noise error term and all lower case roman variables are expressed as logs. The error-correction term in (1) ensures that the price level converges to $\mathrm{p}^{*}$ in a steady state. We expect $\delta<0$ and so can use estimates of $(1+\delta)$ as a simple measure of persistence. As is well known, this model of inflation persistence can be derived from a structural model of forward-looking price adjustment, by assuming that $\Delta_{4} p^{*}{ }_{t}$ follows an autoregressive process (for details, see, for example, Nickell, 1985, Alogoskoufis and Smith, 1991 and Tinsley, 2002). Structural model of forward-looking price adjustment can be derived by assuming that firms minimize an intertemporal loss function where per-period losses depend on the quadratic difference between $p$ and $p^{*}$ and where firms also face quadratic costs of price adjustment (Rotemberg, 1987). A similar equation can also be derived using a model in which there is a fixed probability that firms can adjust price in any period (Calvo, 1983, Gali and Gertler, 1999) or a model of overlapping price adjustment (Taylor, 1979). For a discussion of these models, see Rotemberg (1987) and Roberts (1995). For recent examples of similar models in a UK context, see e.g. Bank of England (1999), Hendry (2001), Balakrishnan and Lopez-Salido (2002) and Kara and Nelson (2002). We assume that the steady-state price level is determined by

$$
p_{t}^{*}=\pi^{\prime} z_{t}+u_{t}
$$

where $z_{t}$ is a (kx1) vector of explanatory variables and $\pi$ is a (kx1) vector of parameters.

There are two alternative methodologies for estimation of the model. The first methodology exploits the nonstationary nature of the data by 
estimating the parameters of (2) as a cointegrating relationship. We then estimate

$$
\Delta_{4} p_{t}=\beta(L) \Delta_{4} p_{t-1}+\gamma(L) \Delta_{4} \hat{p}_{t}^{*}+\delta\left(p-\hat{p}^{*}\right)_{t-4}+\varepsilon_{t}
$$

where $\hat{p}_{t}{ }_{t}=\hat{\pi}^{\prime} z_{t}$ and $\hat{\pi}$ are the estimates of (2). The second methodology substitutes (2) into (1) and estimates

$$
\Delta_{4} p_{t}=\beta(L) \Delta_{4} p_{t-1}+\gamma(L) \Delta_{4} \pi^{\prime} \Delta z_{t}+\delta\left(p-\pi^{\prime} z\right)_{t-4}+\varepsilon_{t}
$$

We choose to use the first methodology, not least because it requires estimation of a smaller number of parameters, which is an important consideration when estimating non-linear models ${ }^{1}$.

We specify the steady-state price as

$$
p_{t}^{*}=\pi_{0}+\pi_{1} u l c_{t}+\pi_{2} p_{t}^{w}+u_{t}
$$

where ulc is the natural logarithm of labour costs, $p^{w}$ is the natural logarithm of world prices in domestic currency and $u_{t}$ is a white noise error term. The specification of (5) is quite standard as models similar to (5) have been analysed elsewhere in the literature (e.g. Alogoskoufis, 1990, Hendry, 2001, Clements and Sensier, 2003). We follow Hendry (2001) in estimating (5) using the Engle and Granger (1987) approach.

Estimates of (5) are presented in Table 1. We use quarterly data for 1964Q2-2001Q2. Prices are measured using the GDP deflator, unit labour cost is measured as $\log (\mathrm{W} /(\mathrm{Y} / \mathrm{L}))$, where $\mathrm{W}$ is the hourly wage, $\mathrm{Y}$ is output and $L$ are total hours of work, and $p^{w}$ is an index of import prices in terms of domestic currency. All data were obtained from the ONS databank. ADF and other tests for stationarity show that all three variables in (5) are I(1). This is similar to findings in Hendry (2001). We estimate $\pi_{1}=0.93$ and $\pi_{2}=0.09$.

\footnotetext{
${ }^{1}$ It is possible to combine these approaches. For example, Holly and Turner (2001) estimate a model similar to (4) but where the error correction term is derived from a cointegrating relationship for $\mathrm{p}^{*}$.
} 
These estimates are reasonably close to those obtained by other studies (including those that use the Johansen, 1988, 1995, approach to estimating cointegrating relationships, e.g. Martin, 1997), although the weight on world prices is somewhat smaller than in studies that use annual data over a longer time period. We investigated the robustness of our estimates. We estimated models using the consumer price index to measure prices, used a measure of world export prices to measure $\mathrm{p}^{\mathrm{w}}$ and used weekly rather than hourly wages. We also imposed homogeneity on (5). Although there was some variation in the parameters estimates, the implied values of $p^{*}$ from these experiments were similar ${ }^{2}$. We also estimated a model in which the steady state is a function of the nominal money supply and import prices. Estimates of this model were also cointegrated and the implied values of $p^{*}$ are again broadly similar.

Estimates of our linear model of inflation persistence are presented in column (i) of Table 2. Our preferred specification is

$$
\Delta_{4} p=\alpha_{0}+\alpha_{1} \Delta_{4} p_{t-1}+\alpha_{2} \Delta_{4} p_{t-4}+\alpha_{3} \Delta_{4} p_{t-5}+\alpha_{4} \Delta_{4} \hat{p}_{t}^{*}+\alpha_{5}\left(p-\hat{p}^{*}\right)_{t-4}+\varepsilon_{t}
$$

where $\varepsilon_{t}$ is a white noise error term. This model was obtained from a specification search on a general model that included up to 9 lags of all variables and where the error correction was included at different lag lengths. We were able to omit all lags of $\Delta_{4} \hat{p}_{t}^{*}$ and to include only three lags of $\Delta_{4} p$. The data strongly preferred the error correction term to reflect price disequilibrium at a one-year lag. We include a dummy variable for 1979Q3 to capture the effects of the introduction of VAT (see also, Clements and Sensier, 2003). As the presence of $\Delta_{4} \hat{p}_{t}^{*}$ in (6) might raise simultaneity problems, all inflation models are estimated by instrumental variable techniques using $\Delta_{4} \hat{p}_{t-1}{ }^{*}$ as an instrument. The estimated residuals appear to be white noise. However the estimates are unstable since they fail the parameter stability test.

\footnotetext{
${ }^{2}$ Details of these and all other estimated models referred to in the paper but not explicitly reported, are available from the authors.
} 
The estimates display considerable persistence. The estimate on the error-correction term implies slow but significant adjustment towards the steady state. The finding of substantial persistence is consistent with a large body of evidence using a variety of methodologies (e.g. Bank of England, 1999, Mihov, 2001, Batini and Nelson, 2002, Balakrishnan and Lopez-Salido, 2002, Kara and Nelson, 2002). We investigated the robustness of these findings by estimating models using the alternative measures of $\mathrm{p}^{*}$ referred to above. We also estimated a model based on the alternative methodology in (4). In neither case were there any significant changes to the estimates and the key features of our estimates were unaffected.

We begin our assessment of nonlinearity by testing (6) against a general non-linear alternative using the Lagrange Multiplier (LM) F-test of Luukkonen et al. (1988) We estimate the augmented model

$$
\Delta p_{t}=\phi^{\prime} w_{t}+\phi_{1}^{\prime} \tilde{w}_{t}\left(p-\hat{p}^{*}\right)_{t-d}+\phi_{2}^{\prime} \tilde{w}_{t}\left(p-\hat{p}^{*}\right)_{t-d}^{2}+\phi_{3}^{\prime} \tilde{w}_{t}\left(p-\hat{p}^{*}\right)_{t-d}^{3}+\varepsilon_{t},
$$

for a variety of values of the delay parameter $d$, where å is a white noise error, $W_{t}=\left\{1, \Delta_{4} p_{t-1}, \Delta_{4} p_{t-4}, \Delta_{4} p_{t-5}, \Delta_{4} \hat{p}_{t}{ }_{t},\left(p-\hat{p}^{*}\right)_{t-4} \mathrm{~d} 79 \mathrm{q} 3\right\}^{\prime}$ contains the regressors

from (6) and $\tilde{\mathrm{w}}_{\mathrm{t}}$ are the $w_{t}$ regressors without the constant and the dummy d79q3. Linearity implies the null hypothesis $H_{0}: \phi_{1}^{\prime}=\phi_{2}^{\prime}=\phi_{3}^{\prime}=0$. Table 3 presents the results of our linearity tests. We report $p$-values for 9 values of the delay parameter, $d$. The null hypothesis of linearity is rejected in almost every case.

\section{3) Non-linear Models of Inflation Persistence}

We begin by estimating a series of nonlinear-in-variables models of inflation. We first estimate the Escribano-Granger model (Escribano and Granger, 1998, Escribano and Aparicio, 1999)

$$
\begin{aligned}
& \Delta_{4} p=\alpha_{0}+\alpha_{1} \Delta_{4} p_{t-1}+\alpha_{2} \Delta_{4} p_{t-4}+\alpha_{3} \Delta_{4} p_{t-5}+\alpha_{4} \Delta_{4} \hat{p}_{t}^{*}+\alpha_{5}\left(p-\hat{p}^{*}\right)_{t-4} \\
& +\alpha_{6}\left(p-\hat{p}^{*}\right)^{2}{ }_{t-4}+\alpha_{7}\left(p-\hat{p}^{*}\right)^{3}{ }_{t-4}+\varepsilon_{t}
\end{aligned}
$$


The nonlinear error correction terms allow the speed of adjustment to the steady state to depend on the gap between the price level and the steady-state price. The model thus allows for the size hypothesis but not the asymmetry hypothesis. If $\alpha_{6}=\alpha_{7}=0$, equation (8) simplifies to the linear model in (6). We also consider the asymmetric error correction model of Granger and Lee (1989):

$$
\begin{aligned}
& \Delta_{4} p=\alpha_{0}+\alpha_{1} \Delta_{4} p_{t-1}+\alpha_{2} \Delta_{4} p_{t-4}+\alpha_{3} \Delta_{4} p_{t-5}+\alpha_{4} \Delta_{4} \hat{p}_{t}{ }_{t}+\alpha^{+}{ }_{5}\left(p-\hat{p}^{*}\right)^{+}{ }_{t-4} \\
& +\alpha_{5}^{-}\left(p-\hat{p}^{*}\right)^{-}{ }_{t-4}+\varepsilon_{t}
\end{aligned}
$$

where $\left(p-\hat{p}^{*}\right)^{+}=\left(p-\hat{p}^{*}\right)$ if $\left(p-\hat{p}^{*}\right)>0$ and is zero otherwise, $\left(p-\hat{p}^{*}\right)^{-}=$ $\left(p-\hat{p}^{*}\right)$ if $\left(p-\hat{p}^{*}\right)<0$ and is zero otherwise. This model allows for asymmetric price adjustment by introducing separate effects from positive and negative price deviations. This model therefore allows for the asymmetry hypothesis but not the size hypothesis. If $\alpha^{+}{ }_{5}=\alpha^{-}$, the model simplifies to the linear model. Finally, we also consider a composite model that combines the Escribano-Granger and Granger-Lee models:

$$
\begin{aligned}
& \Delta_{4} p=\alpha_{0}+\alpha_{1} \Delta_{4} p_{t-1}+\alpha_{2} \Delta_{4} p_{t-4}+\alpha_{3} \Delta_{4} p_{t-5}+\alpha_{4} \Delta_{4} \hat{p}_{t}{ }_{t}+\alpha^{+}{ }_{5}\left(p-\hat{p}^{*}\right)^{+}{ }_{t-4} \\
& +\alpha^{-}\left(p-\hat{p}^{*}\right)^{-}{ }_{t-4}+\alpha_{6}\left(p-\hat{p}^{*}\right)^{2}{ }_{t-4}+\alpha_{7}\left(p-\hat{p}^{*}\right)^{3}{ }_{t-4}+\varepsilon_{t}
\end{aligned}
$$

This composite model simplifies to the Escribano-Granger model in (8) if $\alpha^{+}{ }_{5}=\alpha_{5}^{-}$, to the Granger-Lee model in (9) if $\alpha_{6}=\alpha_{7}=0$, and to the linear model in (6) if $\alpha_{6}=\alpha_{7}=0$ and $\alpha^{+}{ }_{5}=\alpha_{5}^{-}$.

Estimates of these models are presented in columns (ii)-(iv) of Table $2^{3}$. All three nonlinear models have a lower standard error and AIC than the linear model, with the composite model providing the best fit. However all three models also fail the parameter stability test. There is strong support for

\footnotetext{
${ }^{3}$ Equations (8)-(10) use the same dynamic specification used in the liner model, (6). We also used the general-to-specific approach to allow the data to determine the dynamic specification of these models. We found that (8)-(10) represent the best specification.
} 
the size hypothesis since we are always able to reject the hypotheses $H_{0}: \alpha_{6}=\alpha_{7}=0$ and estimates of $\alpha_{6}$ and $\alpha_{7}$ in columns (ii) and (iv) are similar. The status of the asymmetry hypothesis is less clear. We are able to reject the hypothesis $H_{0}: \alpha^{+}{ }_{5}=\alpha^{-}$in column (iii) of table 2 but not in column (iv). The estimate of $\alpha^{-}$is wrongly signed and insignificant in column (iii), as is the estimate of $\alpha^{+}$in column (iv) ${ }^{4}$.

These estimates suggest that the persistence of inflation is nonlinear. However the failure of the parameter stability tests suggests that none of these models is entirely satisfactory. We therefore consider alternative models of nonlinear inflation persistence. We will analyse a series of Smooth Transition Error Correction (STECM) models (e.g. van Dijk et al., 2002). These are stochastic state dependent regime-switching models in which inflation persistence is described as the weighted average of different linear models and where the regime weight is a function of the error-correction term.

The first STECM model we consider is the quadratic logistic STECM model

$$
\begin{gathered}
\Delta p_{t}=\theta_{t} M_{1 t}+\left(1-\theta_{t}\right) M_{2 t}+\varepsilon_{t} \\
M_{1 t}=\alpha_{10}+\alpha_{11} \Delta_{4} p_{t-1}+\alpha_{12} \Delta_{4} p_{t-4}+\alpha_{13} \Delta_{4} p_{t-5}+\alpha_{14} \Delta_{4} \hat{p}_{t}^{*}+\alpha_{15}\left(p-\hat{p}^{*}\right)_{t-4} \\
M_{2 t}=\alpha_{20}+\alpha_{21} \Delta_{4} p_{t-1}+\alpha_{22} \Delta_{4} p_{t-4}+\alpha_{23} \Delta_{4} p_{t-5}+\alpha_{24} \Delta_{4} \hat{p}_{t}{ }_{t}+\alpha_{25}\left(p-\hat{p}^{*}\right)_{t-4} \\
\theta_{t}=\operatorname{pr}\left\{\tau^{L} \leq\left(p-\hat{p}^{*}\right)_{t-4} \leq \tau^{U}\right\}=1-\frac{1}{1+e^{-\sigma\left[\left(p-\hat{p}^{*}\right)_{t-4}-\tau^{L}\right]\left[\left(p-\hat{p}^{*}\right)_{t-4}-\tau^{U}\right]}}
\end{gathered}
$$

Equation (11) describes inflation as a weighted average of linear models $M_{1}$ and $M_{2}$. Equations (12) and (13) describe $M_{1}$ and $M_{2}$ as linear errorcorrection models, similar to (6). Equation (14) specifies the regime weight $\theta$ as the probability that the error-correction term $\left(p-\hat{p}^{*}\right)_{t-4}$ lies within the

\footnotetext{
${ }^{4}$ Holly and Turner (2001) estimate a Granger-Lee model or prices in UK manufacturing for 1970-96. They find prices adjust faster when below the steady state.
} 
"regime boundaries" $\tau^{L}$ and $\tau^{U}$. Inflation is determined by $M_{1}$ when prices have been close to their steady state values and by $M_{2}$ when prices have been some way from the steady state.

We model the probability in (14) using a quadratic logistic function. This model has the properties that (i) $\theta$ becomes constant as $\sigma \rightarrow 0$ and (ii) as $\sigma \rightarrow \infty, \theta=0$ if $p_{t}-\hat{p}_{t}{ }^{*}<p^{L}$ or $p_{t}-\hat{p}_{t}{ }^{*}>p^{U}$ and $\theta=1$ if $p^{L}<p_{t}-\hat{p}_{t}{ }^{*}<p^{U}$ (Jansen and Teräsvirta, 1996). We use the fourth lag of the error correction term in (14) because van Dijk and Franses (2000) and van Dijk et al. (2002) recommend using the lag corresponding to the value of $d$ that gives the strongest rejection of the null of linearity in (7). As Table 3 shows, this occurs at $d=4$.

There are size effects in this model, if inflation is less persistent in the outer regime, that is, if $\alpha_{15}<\alpha_{25}$. Granger and Teräsvirta (1993) and Teräsvirta (1998) argue that the Escribano-Granger model can be regarded as an approximation to this STECM model. There are asymmetry effects if $\tau^{L}+\tau^{U} \neq 0$. If so, persistence differs according to the sign of $\left(p-\hat{p}^{*}\right)_{t-4}$. The model simplifies to the linear model in (6) if $\alpha_{1 i}=\alpha_{2 i}$, for $i=0, . ., 5$, in which case there is no difference in behaviour between regimes.

Column (i) of Table 4 presents estimates of the model. The model has a lower standard error and Akaike Information Criterion (AIC) than any of the models in table 2. However, this model also fails the parameter stability test, albeit narrowly. The point estimates of $\alpha_{15}$ and $\alpha_{25}$ are consistent with the size hypothesis. However, we cannot reject $H_{0}: \alpha_{15}=\alpha_{25}$. We cannot reject $H_{0}: \tau^{L}+\tau^{U}=0$, so there is no support for the asymmetry hypothesis in this model. Estimates of the $\tau$ parameters show that persistence begins to fall as the gap between the price level and steady state prices rises above $3.5 \%$. We also reject $H_{0}: \alpha_{1 \mathrm{i}}=\alpha_{2 \mathrm{i}}$ for $\mathrm{i}=0, . ., 5$, so we reject the hypothesis that inflation persistence is linear. The estimate of $\sigma$ is large, implying rapid transitions between the regimes. However, this parameter is imprecisely estimated as the likelihood function is very insensitive to this parameter (see the detailed discussion in van Dijk et al., 2002).

In our second STECM model we replace (14) with 


$$
\theta_{t}=\operatorname{pr}\left\{\tau \geq\left(p-\hat{p}^{*}\right)_{t-4}\right\}=1-\frac{1}{1+e^{-\sigma\left[\left(p-\hat{p}^{*}\right)_{t-4}-\tau\right]}}
$$

giving the logistic STECM model. Inflation, as before, is a weighted average of $M_{1}$ and $M_{2}$, but in this case the regime weight is the probability that the error-correction term $\left(p-\hat{p}^{*}\right)_{t-4}$ is less than the single regime boundary $\tau$. There are no size effects in this model. However there are asymmetry effects if $\alpha_{15} \neq \alpha_{25}$, in which case the persistence of inflation depends on the sign of $\left(p-\hat{p}^{*}\right)_{t-4}$. This model might therefore be seen as a generalisation of the Granger-Lee model. As with the quadratic logistic model, this model simplifies to the linear model in (6) if $\alpha_{1 i}=\alpha_{2 i}$, for $i=0, . ., 5$.

Our estimates are presented in column (ii) of Table 4. This model does not fit the data particularly well. The standard error and AIC are higher than for the quadratic logistic model ${ }^{5}$, are no better than those of the Granger-Lee model and are higher than those of the composite model of column (iv) of table 4. This model also fails the parameter stability test. We cannot reject the hypothesis $H_{0}: \alpha_{15}=\alpha_{25}$. There is therefore no evidence of asymmetry in this model. However, we can reject the hypothesis $H_{0}: \alpha_{1 \mathrm{i}}=\alpha_{2 \mathrm{i}}$ for $\mathrm{i}=0, \ldots, 5$, so this model cannot be simplified to the linear model. We estimate that $\tau=-3.65$, suggesting that persistence changes when prices are more than $3.65 \%$ below the steady state, which is similar to the estimated lower bound in (14). However, this estimate is poorly determined.

Our final STECM model is

$$
\Delta p_{t}=\theta_{1 t} M_{1 t}+\theta_{2 t} M_{2 t}+\left(1-\theta_{1 t}-\theta_{2 t}\right) M_{3 t}+\varepsilon_{t}
$$

where $M_{1}$ and $M_{2}$ are given by (12) and (13) and $M_{3}$ is given by

\footnotetext{
${ }^{5}$ Van Dijk and Franses (2000) and Van Dijk et al. (2002) propose further tests, based on estimates of (6), to discriminate between the quadratic logistic and logistic STECM models. These tests (not reported but available from the authors) favour the quadratic logistic model over the logistic model.
} 


$$
M_{3 t}=\alpha_{30}+\alpha_{31} \Delta_{4} p_{t-1}+\alpha_{32} \Delta_{4} p_{t-4}+\alpha_{33} \Delta_{4} p_{t-5}+\alpha_{34} \Delta_{4} \hat{p}_{t}^{*}+\alpha_{35}\left(p-\hat{p}^{*}\right)_{t-4}
$$

$\theta_{1 t}$ is given by (14) and $\theta_{2 t}$ is

$$
\theta_{2 t}=\operatorname{pr}\left\{\tau^{L} \geq\left(p-\hat{p}^{*}\right)_{t-4}\right\}=1-\frac{1}{1+e^{-\sigma\left[\left(p-\hat{p}^{*}\right)_{t-4}-\tau^{L}\right]}}
$$

In this three-regime STECM ${ }^{6}$, equation (11) describes inflation as a weighted average of linear models $M_{1}, M_{2}$ and $M_{3}{ }^{7}$. $M_{3}$ has more influence on inflation when the probability that the error-correction term is above the upper "regime boundary" $\tau^{U}$ is higher; similarly, $\mathrm{M}_{2}$ has a greater impact on inflation when it is more likely that the error-correction term is below the lower "regime boundary" of $\tau^{L}$ and the inner regime $M_{1}$ has more impact when the probability that the error-correction term is between these bounds is higher.

There are size effects in this model, if inflation is less persistent in the outer regimes, that is, if $\alpha_{15}<\alpha_{25}$ or $\alpha_{15}<\alpha_{35}$. There will be asymmetry effects if the regime boundaries are asymmetric, that is $\tau^{L}+\tau^{U} \neq 0$ or if persistence differs between the upper and lower regimes, so $\alpha_{25} \neq \alpha_{35}$. This model allows therefore for a more extensive set of asymmetry effects than other models. The model simplifies to the quadratic logistic STECM if $\alpha_{2 i}=\alpha_{3 i}$, for $i=0, . ., 5$, in which case behaviour in the upper and lower regimes is the same. The model simplifies to the logistic STECM if either $\alpha_{1 i}=\alpha_{2 i}$ or $\alpha_{1 i}=\alpha_{3 i}$, for $i=0, \ldots, 5$, in which case the inner regime is identical to one of the outer regimes. Finally, the model simplifies to the linear model if $\alpha_{1 i}=\alpha_{2 i}$ and $\alpha_{1 i}=\alpha_{3 i}$, for $i=0, . ., 5$, in which case all regimes are identical.

Our estimates are presented in column (iii) of Table 4. The model has a lower standard error and AIC than any of the other models considered in this paper. It is also the only model that does not fail the parameter stability

\footnotetext{
${ }^{6}$ This model belongs to the class of multiple-regime smooth transition models. Other studies in the area include van Dijk and Franses (1999) who apply a four-regime model to US output, Öcal and Osborn (2000) who estimate a three-regime model for the UK consumption and production and Sensier et al (2002) who apply a four-regime model to UK output.

${ }^{7}$ After some experimentation, we excluded $\Delta_{4} p_{t-4}$ and $\Delta_{4} p_{t-5}$ from $\mathrm{M}_{2}$ to improve the precision of our estimates.
} 
test. As a result, we regard this as our preferred model of inflation persistence. We can reject the restrictions that would simplify this model to the quadratic logistic, logistic or linear models. There is again support for the size hypothesis since although we cannot reject $H_{0}: \alpha_{15}=\alpha_{25}$, we can reject both $H_{0}: \alpha_{15}=\alpha_{35}$ and $H_{0}: \alpha_{15}=\alpha_{25}=\alpha_{35}$. There is also support for the asymmetry hypothesis in this model since, although we cannot reject $H_{0}: \tau^{L}+\tau^{U}=0$, we can reject $H_{0}: \alpha_{25}=\alpha_{35}$. Thus, there is asymmetry because, although the regime boundaries are symmetric, there is less persistence in the upper regime than the lower regime. We therefore find that inflation adjusts more rapidly when prices are above the steady state level. Estimates of the $\tau$ parameters are similar to those of the quadratic logistic model. The $\sigma$ parameter is estimated to be rather small for the boundary between the middle and upper regimes which implies a rather smooth change in inflation persistence as this regime boundary is crossed, but to be large for the boundary between the middle and lower regimes which implies a rapid change in behaviour for this transition.

We investigated the robustness of these results by examining the argument that the outer regimes simply model outliers corresponding to periods when prices were furthest from the steady state. To evaluate this, we estimated a model that augmented the linear model in (6) with dummy variables for those periods corresponding to being in the outer regimes in estimates of our preferred model. Estimates of this augmented linear model explain the data better than the linear model but considerably worse than the STECM. Furthermore, estimates of the parameters of (6) were little affected by the inclusion of the dummy variables and the estimated residuals from the augmented model were non-normal.

\section{4) Implications}

This section considers the implications of our results. In all our nonlinear models, the persistence of inflation has varied with the errorcorrection term. Figure 1 plots the error-correction term $\left(p-\hat{p}^{*}\right)_{-4}$ against the 
estimated regime boundaries from our final, preferred, STECM model. We observe that inflation has been determined by the middle regime for most of the sample but that the error-correction term has moved into the outer regimes in periods of macroeconomic stress. Prices were up to $5 \%$ above steady state in the early 1970 s, up to $10 \%$ below steady state during the inflationary episode of the mid-1970s, up to $5 \%$ above steady state in the early 1980 s and up to $5 \%$ below steady state during the late 1980 s and early 1990s.

Figure 2 shows the implications of this for the persistence of inflation by plotting a simple measure of the persistence of inflation, calculated as

$$
\text { persist }_{t}=\theta_{1 t}\left(1+\alpha_{15}\right)+\theta_{2 t}\left(1+\alpha_{25}\right)+\left(1-\theta_{1 t}-\theta_{2 t}\right)\left(1+\alpha_{35}\right)
$$

We note that inflation is less persistent in periods of greatest macroeconomic stress. As the economy moved into the upper regime in 1973, the upper regime rapidly became dominant. The persistence of inflation fell markedly and the economy quickly moved back into the inner regime. The persistence of inflation again fell in late 1974, when the economy entered the lower regime. The fall in persistence was less abrupt and steep and the economy remained in the lower regime until 1976. The persistence of inflation dipped sharply in 1983, when the economy again briefly crossed into the upper regime briefly. Thereafter the economy was in the lower regime from 1990 to 1992 following the inflationary surge of the late 1980s. The economy has remained in the middle regime since the introduction of inflation targets in 1992. Prices have been above their steady state values for most of this period, especially since the granting of Central Bank independence in 1997. This suggests there has been little suppressed inflationary pressure in recent years.

Finally, we consider the dangers of using a linear model of inflation persistence. Figure 3 plots a simple measure of the relative performance of the linear and three-regime STECM model:

$$
\text { gap }=\left|\hat{\pi}^{L}-\pi\right|_{t}-\left|\hat{\pi}^{3 R}-\pi\right|_{t}
$$


This is the difference between the absolute value of the residual from estimates of the linear model in (6) and the absolute value of the residual from estimates of the three-regime STECM model, where $\hat{\pi}^{L}$ is the predicted value of inflation from the linear model and $\hat{\pi}^{3 R}$ is the predicted value of inflation from the three-regime STECM model. A large positive value of this variable indicates a period in which the STECM fits the data substantially better than the linear model. We note that the linear model is especially weak in periods of macroeconomic stress. This suggests the linear model is adequate when prices are close to steady state but inadequate in periods of macroeconomic stress. Thus we can conclude that the dangers of using a linear model are greatest in periods of greatest macroeconomic difficulty.

\section{5) Conclusion}

This paper has investigated the persistence of inflation in the UK over the past 35 years. We have found strong evidence that the persistence of inflation is nonlinear and is best captured using a three-regime STECM model. We have found evidence of both size and asymmetry effects. This means that the persistence of inflation increases as prices move further from the steady state and that the rate at which this happens depends on whether

prices are above or below the steady state. Our results imply that inflation will respond more strongly and more rapidly to changes in interest rates when the price level is further away from the stead-state level. This has implications for optimal monetary policy.

Our work can be extended in several ways. The theory of nonlinear price adjustment is at present very underdeveloped. The model of Ball and Mankiw (1995) might provide a way forward here. This model combines timedependent and state-dependent models of price adjustment by allowing firms to adjust price more frequently if they are willing to pay an additional cost. Since firms will be more willing to pay this cost when prices are further from their optimal values, the resulting model might well exhibit the sort of size and asymmetry effects investigated in this paper. 
It would also be interesting to examine whether nonlinear adjustment with size and asymmetry effects can be elevated into a stylized fact, by considering inflation in other countries. If it can, then nonlinear adjustment of inflation might be incorporated into models of monetary policy, building on existing work that considers the impact of a nonlinear Phillips Curve (eg. Dolado et al, 2002) 
Table 1

Estimates of the steady state price equation (5) 1964Q2-2001Q2

\begin{tabular}{|l|l|}
\hline & Least Squares estimates \\
\hline & \\
\hline Constant & $-0.104(0.010)$ \\
\hline Unit labour cost (ulc) & $0.933(0.014)$ \\
\hline World prices $\left(\mathrm{p}^{\mathrm{w}}\right)$ & $0.089(0.015)$ \\
\hline & \\
\hline standard error of the regression & 0.025 \\
\hline Durbin-Watson & 0.214 \\
\hline & \\
\hline
\end{tabular}

Note: Numbers in parentheses are the standard errors of the estimates. 
Table 2

Estimates of alternative inflation models

\begin{tabular}{|c|c|c|c|c|}
\hline & (i) & (ii) & (iii) & (iv) \\
\hline & Linear model & Escribano-Granger & Granger-Lee & Composite \\
\hline equation & (6) & (8) & (9) & (10) \\
\hline sample & 1965Q2-2001Q2 & 1965Q2-2001Q2 & 1965Q2-2001Q2 & 1965Q2-2001Q2 \\
\hline$\Delta_{4} p_{t-1}$ & $0.764(0.074)$ & $0.739(0.069)$ & $0.742(0.072)$ & $0.736(0.069)$ \\
\hline$\Delta_{4} p_{t-4}$ & $-0.416(0.077)$ & $-0.391(0.074)$ & $-0.3750 .075)$ & $-0.378(0.074)$ \\
\hline$\Delta_{4} p_{t-5}$ & $0.324(0.059)$ & $0.321(0.055)$ & $0.310(0.056)$ & $0.308(0.055)$ \\
\hline$\Delta_{4} \hat{p}^{*}{ }_{t}$ & $0.264(0.043)$ & $0.280(0.040)$ & $0.273(0.041)$ & $0.282(0.040)$ \\
\hline$\left(p-\hat{p}^{*}\right)_{t-4}$ & $-0.090(0.035)$ & $-0.065(0.041)$ & & \\
\hline$\left(p-\hat{p}^{*}\right)_{t-4}^{2}$ & & $-0.055(0.013)$ & & $-0.116(0.035)$ \\
\hline$\left(p-\hat{p}^{*}\right)^{3}{ }_{t-4}$ & & $-0.006(0.002)$ & & $-0.009(0.003)$ \\
\hline$\left(p-\hat{p}^{*}\right)^{+}{ }_{t-4}$ & & & $-0.288(0.071)$ & $0.256(0.175)$ \\
\hline$\left(p-\hat{p}^{*}\right)_{t-4}^{-}$ & & & $0.042(0.054)$ & $-0.344(0.155)$ \\
\hline d79q3 & $3.099(0.875)$ & $3.092(0.821)$ & $3.174(0.847)$ & $2.983(0.816)$ \\
\hline standard error & 0.854 & 0.800 & 0.826 & 0.792 \\
\hline $\mathrm{AIC}$ & 2.565 & 2.449 & 2.511 & 2.431 \\
\hline Durbin-Watson & 1.990 & 1.870 & 1.950 & 1.830 \\
\hline F ar & $1.59[0.18]$ & $1.42[0.23]$ & $1.89[0.12]$ & $1.20[0.31]$ \\
\hline F het & $1.49[0.14]$ & $1.04[0.42]$ & $1.32[0.21]$ & $1.05[0.40]$ \\
\hline F arch & $1.52[0.20]$ & $0.60[0.66]$ & $1.01[0.40]$ & $0.61[0.65]$ \\
\hline$\chi^{2}$ normality & $4.20[0.12]$ & $4.00[0.13]$ & $2.61[0.27]$ & $4.47[0.11]$ \\
\hline F param. stability & $2.46[0.00]$ & $2.81[0.00]$ & $3.30[0.00]$ & $2.45[0.00]$ \\
\hline $\begin{array}{l}\text { No size effects } \\
H_{0}: \alpha_{6}=\alpha_{7}=0\end{array}$ & & $9.71[0.00]$ & & $6.16[0.00]$ \\
\hline $\begin{array}{l}\text { No asymmetry } \\
\text { effects } \\
H_{0}: \alpha^{+}{ }_{5}=\alpha^{-}{ }_{5}\end{array}$ & & & $10.00[0.00]$ & $3.51[0.06]$ \\
\hline
\end{tabular}

Notes: Estimates of the intercept term are not reported. d79q3 refers to a dummy variable discussed in the main text. Numbers in parentheses are the standard errors of the estimates. $F$ ar is the Lagrange Multiplier $\mathrm{F}$ test for residual serial correlation of up to fourth order. $\mathrm{F}$ arch is the fourth order Autoregressive Conditional Heteroskedasticity $\mathrm{F}$ test. $\chi^{2}$ normality is a Chi-square test for normality. $\mathrm{F}$ het is an $\mathrm{F}$ test for heteroskedasticity. F param. stability is an F test of parameter stability (see Lin and Teräsvirta, 1994, and 
Eitrheim and Teräsvirta, 1996). Numbers in square brackets are the probability values of the test statistics. AIC is the Akaike Information Criterion. Size effect and asymmetry effect tests are F-tests. 
Table 3

Linearity tests

\begin{tabular}{|l|l|}
\hline Delay parameter $(\mathrm{d})$ & Transition variable: $\left(\mathrm{p}-\hat{\mathrm{p}}^{*}\right)_{\mathrm{t}-\mathrm{d}}$ \\
\hline 1 & 0.017 \\
\hline 2 & 0.071 \\
\hline 3 & 0.016 \\
\hline 4 & $0.008^{*}$ \\
\hline 5 & 0.009 \\
\hline 6 & 0.009 \\
\hline 7 & 0.108 \\
\hline 8 & 0.038 \\
\hline 9 & 0.103 \\
\hline
\end{tabular}

Notes: The Table reports the $p$-values of the linearity F-test for equation (7) in the text. Under the null, $\mathrm{H}_{0}: \phi_{1}^{\prime}=\phi_{2}^{\prime}=\phi_{3}^{\prime}=0$.

* denotes the minimum probability value of the $\mathrm{H}_{0}$ test over the interval $1 \mathrm{~d} 9$. 
Table 4

Estimates of smooth transition inflation models

\begin{tabular}{|c|c|c|c|}
\hline & $\begin{array}{c}\text { Quadratic logistic } \\
\text { STECM }\end{array}$ & Logistic STECM & $\begin{array}{c}\text { Three-regime } \\
\text { STECM }\end{array}$ \\
\hline Sample & 1965Q2-2001Q2 & 1965Q2-2001Q2 & 1965Q2-2001Q2 \\
\hline d79q3 & $2.884(0.812)$ & $3.119(0.848)$ & $2.835(0.804)$ \\
\hline \multicolumn{4}{|l|}{$M_{1}$} \\
\hline$\Delta_{4} p_{t-1}$ & $0.691(0.059)$ & $0.673(0.176)$ & $0.684(0.060)$ \\
\hline$\Delta_{4} p_{t-4}$ & $-0.332(0.077)$ & $-0.336(0.207)$ & $-0.327(0.080)$ \\
\hline$\Delta_{4} p_{t-5}$ & $0.278(0.059)$ & $0.315(0.165)$ & $0.270(0.061)$ \\
\hline$\Delta_{4} \hat{p}_{t}^{*}$ & $0.309(0.030)$ & $0.273(0.124)$ & $0.313(0.031)$ \\
\hline$\left(p-\hat{p}^{*}\right)_{t-4}$ & $-0.152(0.044)$ & $-0.195(0.313)$ & $-0.117(0.055)$ \\
\hline \multicolumn{4}{|l|}{$M_{2}$} \\
\hline$\Delta_{4} p_{t-1}$ & $0.678(0.148)$ & $0.726(0.061)$ & $0.477(0.110)$ \\
\hline$\Delta_{4} p_{t-4}$ & $-0.357(0.187)$ & $-0.353(0.081)$ & \\
\hline$\Delta_{4} p_{t-5}$ & $0.329(0.151)$ & $0.284(0.062)$ & \\
\hline$\Delta_{4} \hat{p}_{t}^{*}$ & $0.271(0.092)$ & $0.287(0.031)$ & $0.379(0.093)$ \\
\hline$\left(p-\hat{p}^{*}\right)_{t-4}$ & $-0.250(0.105)$ & $-0.197(0.044)$ & $-0.200(0.119)$ \\
\hline \multicolumn{4}{|l|}{$M_{3}$} \\
\hline$\Delta_{4} p_{t-1}$ & & & $0.921(0.254)$ \\
\hline \multicolumn{4}{|l|}{$\Delta_{4} p_{t-4}$} \\
\hline \multicolumn{4}{|l|}{$\Delta_{4} p_{t-5}$} \\
\hline$\Delta_{4} \hat{p}_{t}^{*}$ & & & $0.157(0.147)$ \\
\hline$\left(p-\hat{p}^{*}\right)_{t-4}$ & & & $-0.819(0.324)$ \\
\hline$\tau$ & & $-3.652(169.91)$ & \\
\hline$\tau^{\mathrm{L}}$ & $-3.658(0.811)$ & & $-3.834(0.004)$ \\
\hline$\tau^{\mathrm{U}}$ & $3.968(0.065)$ & & $3.293(0.391)$ \\
\hline$\sigma$ & $27.021(175.65)$ & $228.54(1922.3)$ & \\
\hline$\sigma_{\mathrm{L}}$ & & & $251.02(217.73)$ \\
\hline
\end{tabular}




\begin{tabular}{|l|l|l|l|}
\hline$\sigma_{\mathrm{U}}$ & & & $3.982(2.506)$ \\
\hline $\begin{array}{l}\text { Regression } \\
\text { standard error }\end{array}$ & 0.792 & 0.829 & 0.782 \\
\hline AIC & 2.433 & 2.534 & 2.412 \\
\hline Durbin-Watson & 1.780 & 2.010 & 1.830 \\
\hline F ar & $1.45[0.22]$ & $1.66[0.16]$ & $1.36[0.25]$ \\
\hline F het & $0.64[0.91]$ & $0.84[0.67]$ & $0.53[0.98]$ \\
\hline F arch & $0.51[0.73]$ & $1.42[0.23]$ & $0.56[0.69]$ \\
\hline$\chi^{2}$ normality & $6.39[0.04]$ & $6.04[0.05]$ & $8.05[0.02]$ \\
\hline F param. stability & $1.64[0.04]$ & $1.92[0.02]$ & $1.25[0.21]$ \\
\hline Test $\alpha_{15}=\alpha_{25}$ & $0.90[0.34]$ & $0.00[0.99]$ & $0.34[0.56]$ \\
\hline Test $\alpha_{15}=\alpha_{35}$ & & & $8.65[0.00]$ \\
\hline Test $\alpha_{25}=\alpha_{35}$ & & & $9.85[0.00]$ \\
\hline Test $\tau^{L}+\tau^{U}=0$ & $0.01[0.98]$ & & $2.13[0.15]$ \\
\hline Test $\alpha_{15}=\alpha_{25}=\alpha_{35}$ & & & $5.05[0.00]$ \\
\hline & & & $5.11[0.00]$ \\
\hline $\begin{array}{l}\text { Test against } \\
\text { linear model }\end{array}$ & $5.25[0.00]$ & $2.62[0.00]$ & $5.10[0.00]$ \\
\hline $\begin{array}{l}\text { Test against } \\
\text { quadratic model }\end{array}$ & & & $4.81[0.00]$ \\
\hline $\begin{array}{l}\text { Test against } \\
\text { logistic model } \\
\left(\alpha_{1 i}=\alpha_{2 i}\right)\end{array}$ & & & \\
\hline $\begin{array}{l}\text { Test against } \\
\text { logistic model } \\
\left(\alpha_{1 i}=\alpha_{3 i}\right)\end{array}$ & & & \\
\hline Notes: & & & \\
\hline
\end{tabular}

Notes: Estimates of the intercept term for each regime $M_{1}, M_{2}$ and $M_{3}$ are not reported. Numbers in parentheses are the standard errors of the estimates. For the quadratic logistic model, $\sigma$ is made dimension-free by dividing it by the variance of $\left(p-\hat{p}^{*}\right)_{t-4}$. For the logistic model, $\sigma$ is divided by the standard deviation of $\left(p-\hat{p}^{*}\right)_{t-4}$ (see Granger and Teräsvirta, 1993). The tests against the linear, size and asymmetry model are F-tests. 
Figure 1: The error-correction term with regime boundaries from the threeregime STECM

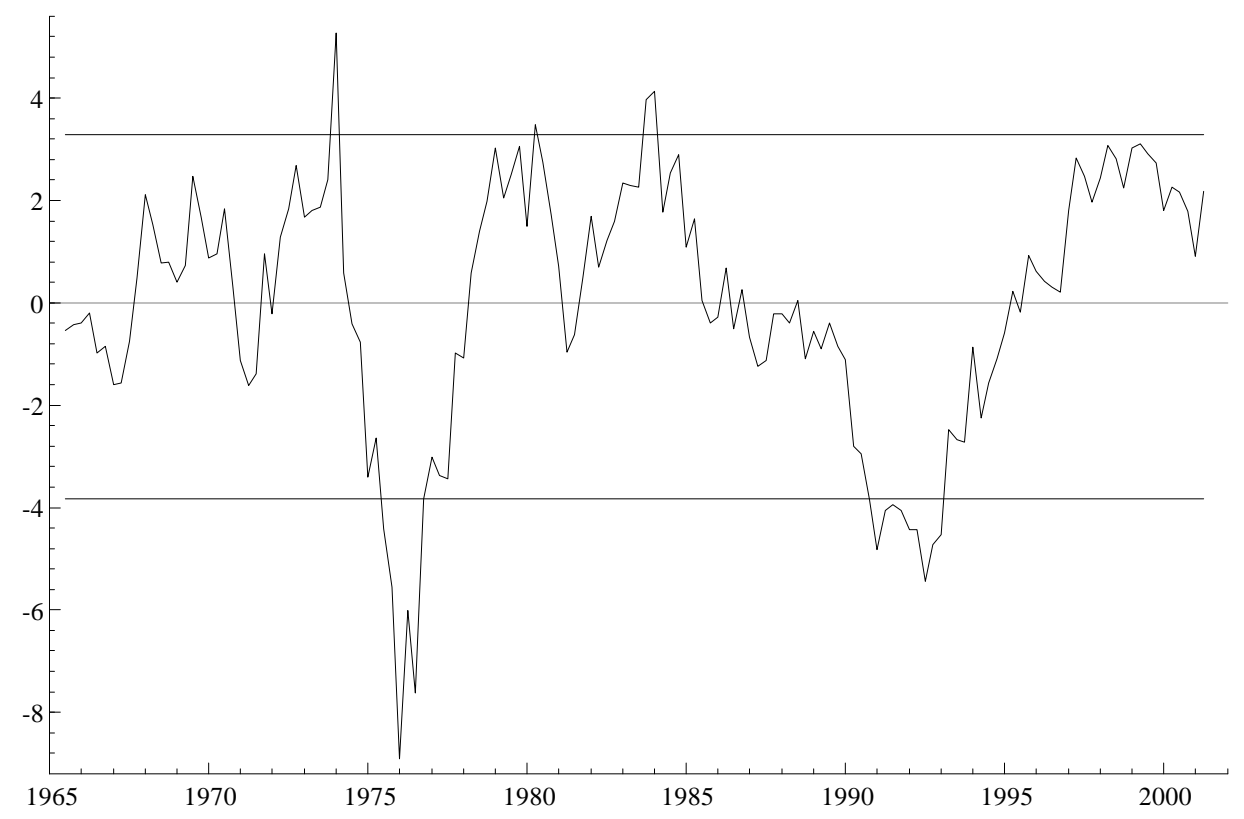

Note: the graph plots the residuals from the estimates of (5) reported in table 1 and the estimates of $\tau^{L}$ and $\tau^{\cup}$ presented in column (iii) of table 4 .

Figure 2: The persistence of inflation

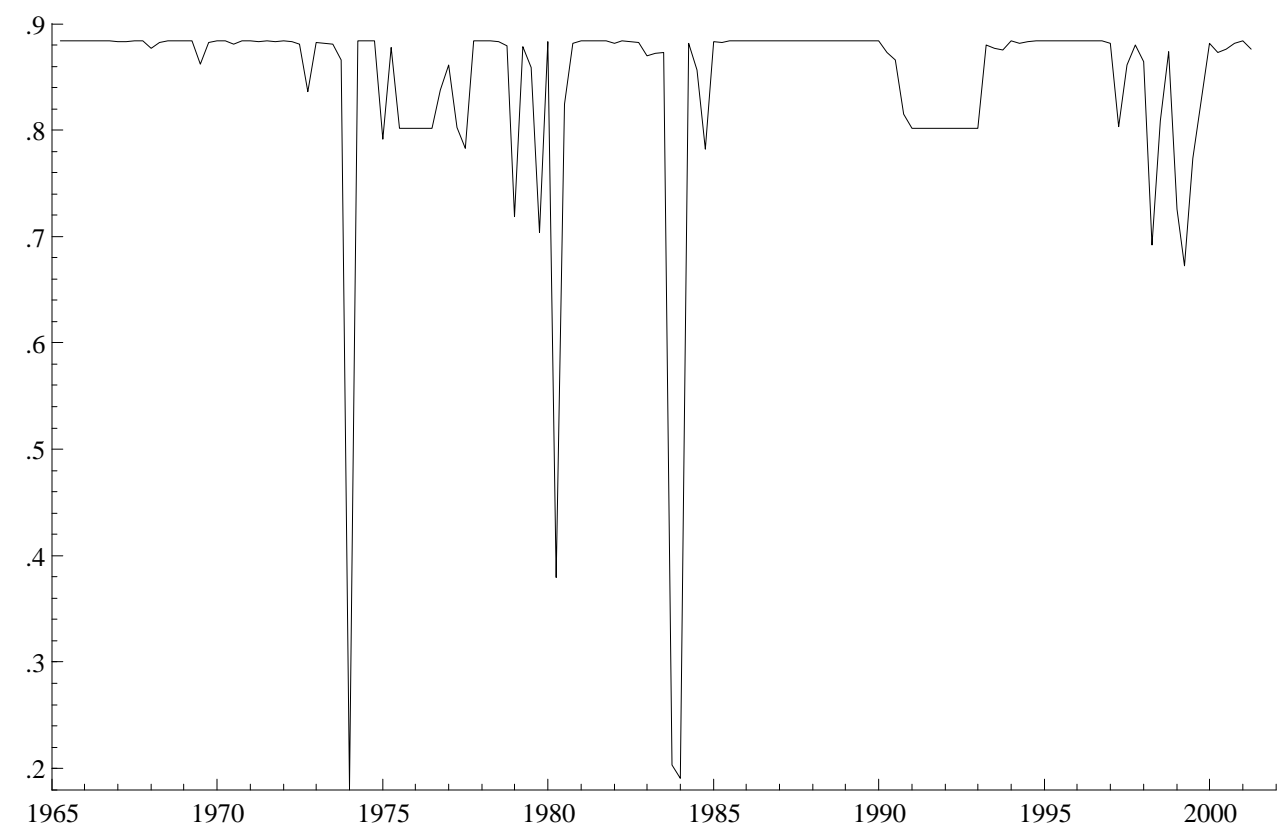

Note: The figure plots persist $t_{t}=\theta_{1 t}\left(1+\alpha_{15}\right)+\theta_{2 t}\left(1+\alpha_{25}\right)+\left(1-\theta_{1 t}-\theta_{2 t}\right)\left(1+\alpha_{35}\right)$ 
Figure 3: The Relative Performance of the Linear and three-regime STECM models

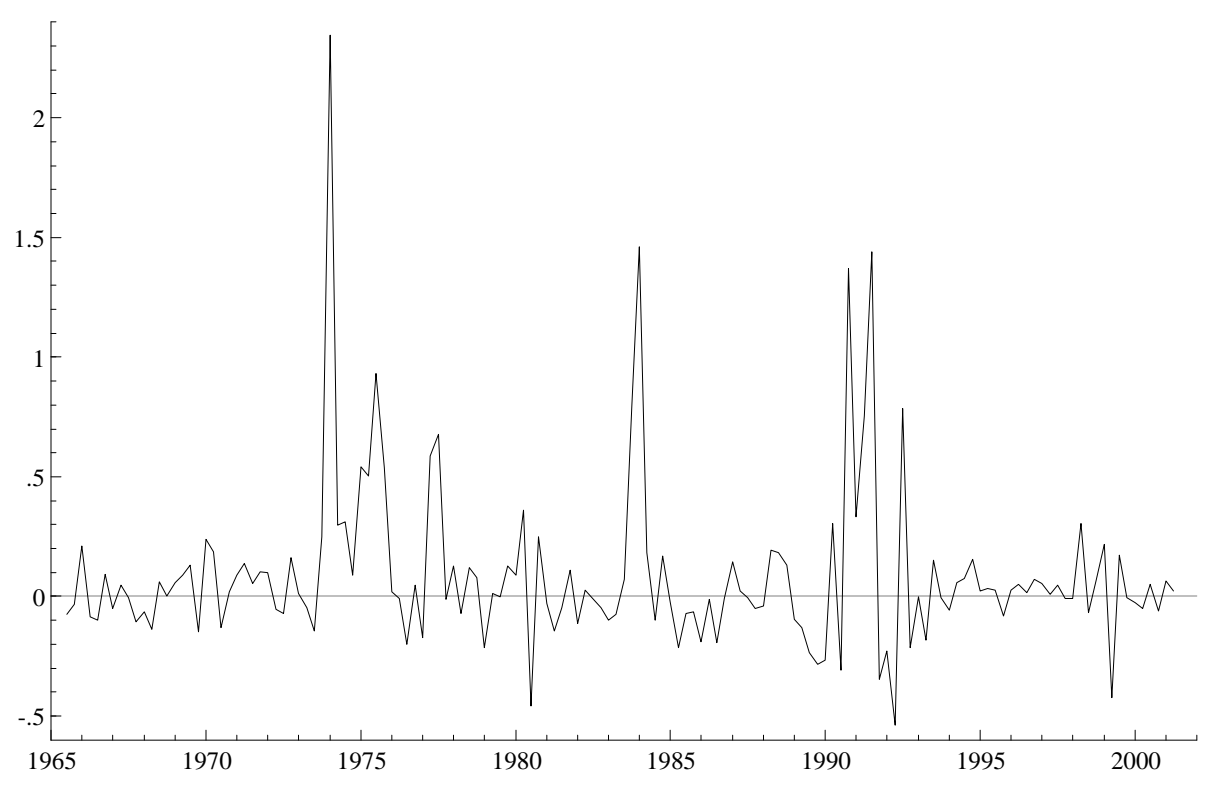

Note: The graph plots gap $=\left|\hat{\pi}^{L}-\pi\right|_{t}-\left|\hat{\pi}^{3 R}-\pi\right|_{t}$, where $\hat{\pi}^{L}$ is the predicted value of inflation from the linear model and $\hat{\pi}^{3 R}$ is the predicted value of inflation from the three-regime STECM model. 


\section{References}

Alogoskoufis, G. (1990), "Traded goods, competitiveness and aggregate fluctuations in the United Kingdom", Economic Journal, 100, 141-163.

Alogoskoufis, G. and R. Smith (1991), "The Phillips Curve, the Persistence of Inflation and the Lucas Critique: Evidence from Exchange Rate Regimes", American Economic Review, 81, 1254-1271.

Balakrishnan, R. and D. Lopez-Salido (2002), "Understanding UK inflation: the role of openess", Working paper No. 164, Bank of England.

Ball, L. and G. Mankiw (1995), "Asymmetric price adjustment and economic fluctuations", Economic Journal, 105, 247-261.

Bank of England (1999), Economic Models at the Bank of England, Bank of England.

Batini, N. and E. Nelson (2002), "The lag from monetary policy actions to inflation: Friedman revisited", MPC Unit paper No. 6, Bank of England.

Bennett, J. and M.A. La Manna (2001), "Reversing the Keynesian asymmetry", American Economic Review, 91, 1556-1563.

Calvo, G. (1983), "Staggered Contracts in a Utility-Maximizing Framework," Journal of Monetary Economics, 12, 383-398.

Clarida, R., J. Galß and M. Gertler (1999), "The Science of Monetary Policy - A New Keynesian Perspective", Journal of Economic Literature, 37, 1661-1707.

Clements, M. and M. Sensier (2003), "Asymmetric output-gap effects in the Phillips curve and mark-up pricing models: Evidence for the US and the UK", Scottish Journal of Political Economy (forthcoming). 
Dolado. J, R. Maria-Dolores and M. Naviera (2002), "Are monetary policy reaction functions asymmetric? The role of nonlinearity in the Phillips curve", mimeo, Universidad Carlos III de Madrid.

Eitrheim, Ø. and T. Teräsvirta (1996), "Testing the adequacy of smooth transition autoregressive models", Journal of Econometrics, 74, 59-75.

Engle, R.F. and C.W.J. Granger (1987), "Cointegration and error-correction: representation, estimation and testing", Econometrica, 55, 251-276.

Escribano, A. and F. Aparicio (1999), "Cointegration: linearity, nonlinearity, outliers and structural breaks in Dahiya, S.B. (ed), The Current State of Economic Science, Spellbound Publications, Vol 1, 383-407.

Escribano, A. and C.W.J. Granger (1998), "Investigating the relationship between gold and silver prices", Journal of Forecasting, 17, 81-107.

Gali, J. and M. Gertler (1999), "Inflation dynamics: a structural econometric analysis", Journal of Monetary Economics, 44, 195-222.

Granger, C.W.J. and T.H. Lee (1989), "Investigation of production, sales and inventory relationships using multicointegration and non-symmetric error correction models", Journal of Applied Econometrics, 4, S145-S159.

Granger, C.W.J. and T. Teräsvirta (1993), Modelling Nonlinear Economic Relationships Oxford University Press, Oxford.

Hendry, D.F. (2001), "Modelling UK Inflation, 1875-1991", Journal of Applied Econometrics, 16, 255-275.

Holly, S. and P. Turner (2001), "Asymmetric adjustment costs, asymmetric pricing and employment: evidence from the UK", Scottish Journal of Political Economy, 48, 69-81. 
Jansen, E.S. and T. Teräsvirta (1996), "Testing parameter constancy and super exogeneity in econometric equations", Oxford Bulletin of Economics and Statistics, 58, 735-768.

Johansen, S. (1988), "Statistical analysis of cointegration vectors", Journal of Economic Dynamics and Control, 12, 231-254.

Johansen, S. (1995), Likelihood-based inference in cointegrated vector autoregressive models, Oxford University Press, Oxford.

Kara, A and E Nelson (2002), "The exchange rate and inflation in the UK", External MPC Unit discussion paper No. 11, Bank of England.

Lin, C-F.J. and T. Teräsvirta, (1994), "Testing the constancy of regression parameters against continuous structural change", Journal of Econometrics, 62, 211-228.

Luukkonen, R., P. Saikkonen and T. Teräsvirta (1988), "Testing linearity against smooth transition autoregressive models", Biometrika, 75, 491-499.

Martin, C. (1997), "Price formation in an open economy: theory and evidence for the United Kingdom, 1951-1991", Economic Journal, 107, 1391-1404.

Mihov, I. (2001), "Monetary policy implementation and transmission in the European Union", Economic Policy, 16, 369-406.

Nickell, S. (1985), Error correction, partial adjustment and all that: an expository note, Oxford Bulletin of Economics and Statistics, 47, 119-129.

Öcal, N. and D.R. Osborn (2000), "Business cycle non-linearities in UK consumption and production", Journal of Applied Econometrics, 15, 27-43.

Roberts, J. (1995), "New Keynesian economics and the Phillips Curve", Journal of Money Credit and Banking, 27, 975-984. 
Rotemberg, J. (1987), The New Keynesian microfoundations", NBER Macroeconomics Annual, 69-114.

Sensier, M., D.R. Osborn and N. Öcal (2002), "Asymmetric interest rate effects for the UK real economy", Oxford Bulletin of Economics and Statistics, 64, 315-339.

Svensson, L. (1997), "Optimal Inflation Targets, 'Conservative Central Bankers' and Linear Inflation Contracts", American Economic Review, 87, 98114.

Taylor, J. (1979), "Staggered Wage-Setting in a Macro Model", American Economic Review, Papers and Proceedings, 69, 108-113.

Teräsvirta, T. (1998), Comment on 'The demand for broad money in the United Kingdom, 1878-1993' by Ericsson, N.R., Hendry, D.F. and Prestwich, K.M, Scandinavian Journal of Economics, 100, 325-328.

Tinsley, P. (2002), "Rational error Correction", Computational Economics, 19, 197-225.

van Dijk, D. and P.H. Franses (1999), "Modeling multiple regimes in the business cycle", Macroeconomic Dynamics, 3, 311-340.

van Dijk, D., Franses, P.H. (2000), "Nonlinear error-correction models for interest rates in the Netherlands", in: Barnett, W.A., Hendry, D.F., Hylleberg, S., Teräsvirta, T., Tjostheim, D., Würtz, A., (Eds.), Nonlinear Econometric Modelling in Time Series Analysis Cambridge University Press, Cambridge, pp. 203-227.

van Dijk, D., T. Teräsvirta, and P.H. Franses (2002), "Smooth transition autoregressive models - a survey of recent developments", Econometric Reviews, 21, 1-47. 
